OPEN ACCESS

Edited by:

Everlon Cid Rigobelo,

Universidade Estadual Paulista, Brazil

Reviewed by:

Asma Imran,

National Institute for Biotechnology and Genetic Engineering, Pakistan

Manuel Espinosa-Urgel,

Estación Experimental de

Zaidin, Spain

*Correspondence:

Jesús Muñoz-Rojas

joymerre@yahoo.com.mx

Specialty section:

This article was submitted to

Crop Biology and Sustainability,

a section of the journal

Frontiers in Sustainable Food Systems

Received: 13 October 2020 Accepted: 10 December 2020

Published: 20 January 2021

Citation:

Molina-Romero D, Juárez-Sánchez $S$, Venegas B, Ortiz-González CS,

Baez A, Morales-García YE and

Muñoz-Rojas J (2021) A Bacterial

Consortium Interacts With Different

Varieties of Maize, Promotes the Plant

Growth, and Reduces the Application

of Chemical Fertilizer Under Field

Conditions.

Front. Sustain. Food Syst. 4:616757. doi: 10.3389/fsufs. 2020.616757

\section{A Bacterial Consortium Interacts With Different Varieties of Maize, Promotes the Plant Growth, and Reduces the Application of Chemical Fertilizer Under Field Conditions}

\author{
Dalia Molina-Romero ${ }^{1,2}$, Saúl Juárez-Sánchez ${ }^{1}$, Berenice Venegas ${ }^{1}$, \\ Cindy S. Ortíz-González ${ }^{1}$, Antonino Baez ${ }^{2}$, Yolanda E. Morales-García ${ }^{1,2}$ and \\ Jesús Muñoz-Rojas ${ }^{2 *}$
}

${ }^{1}$ Laboratorio de Biología Molecular y Microbiología, Facultad de Ciencias Biológicas, Benemérita Universidad Autónoma de Puebla, Edificio 112-A, Ciudad Universitaria, Puebla, Mexico, ${ }^{2}$ Ecology and Survival of Microorganisms Group, Laboratorio de Ecología Molecular Microbiana, Centro de Investigaciones en Ciencias Microbiológicas, Instituto de Ciencias, Benemérita Universidad Autónoma de Puebla, Edificio IC11, Ciudad Universitaria, Puebla, Mexico

The success of beneficial bacteria in improving the crop growth and yield depends on an adequate plant-bacteria interaction. In this work, the capability of Azospirillium brasilense Sp7, Pseudomonas putida KT2440, Acinetobacter sp. EMM02, and Sphingomonas sp. OF178A to interact with six maize varieties was evaluated by both single-bacterium application and consortium application. The bacterial consortium efficiently colonized the rhizosphere of the autochthonous yellow and $\mathrm{H} 48$ hybrid varieties. Bacterial colonization by the consortium was higher than under single-bacterium colonization. The two maize varieties assayed under greenhouse conditions showed increased plant growth compared to the control. The effect of consortium inoculation plus 50\% fertilization was compared with the $100 \%$ nitrogen fertilization under field conditions using the autochthonous yellow maize. Inoculation with the consortium plus 50\% urea produced a similar grain yield compared to $100 \%$ urea fertilization. However, a biomass decrease was observed in plants inoculated with the consortium plus 50\% urea compared to the other treatments. Furthermore, the safety of these bacteria was evaluated in a rat model after oral administration. Animals did not present any negative effects, after bacterial administration. In conclusion, the bacterial consortium offers a safety alternative that can reduce chemical fertilization by half while producing the same crop yield obtained with $100 \%$ fertilization. Decreased chemical fertilization could avoid contamination and reduce the cost in agricultural practices.

Keywords: consortium, bacterial safety, urea reduction, crop yield, field experiments 


\section{INTRODUCTION}

The study of the interaction of plant growth-promoting rhizobacteria (PGPR) with plants of agricultural interest has led to the development of biofertilizers or bio-inoculants (Kumar et al., 2007; Zahid et al., 2015). These rhizobacteria have the ability to increase plant growth and yield (Naveed et al., 2008). Furthermore, the rhizobacteria can protect plants from phytopathogens (Wang et al., 2012; Singh et al., 2014), increase plant tolerance to high concentrations of heavy metals (Hassan et al., 2014; Ramírez et al., 2019, 2020), and perform bioremediation (Glick, 2003; Sheng et al., 2012).

The rhizobacteria with the capability to promote the growth of plants include several species such as Pseudomonas flourescens and $P$. aeruginosa for maize (Adjanohoun et al., 2011); Paenibacillus lentimorbus and Bacillus amyloliquefaciens for rice (Bisht and Chauhan, 2020); Rhizobium pisi and Pseudomonas monteilii for bean (Sánchez et al., 2014); and Bacillus subtilis and Pseudomonas fluorescens for Capsicum annumen (Sundaramoorthy et al., 2012). Furthermore, some of those bacteria perform control of fungal diseases produced by Fusarium solani (Sundaramoorthy et al., 2012).

In the last two decades, the synergy of two or more than two PGPRs has been investigated after they are simultaneously inoculated in the same plant (Lally et al., 2017; Mpanga et al., 2019). The application of consortia can increase the production and growth of maize and cucumber plants compared to the inoculation of individual bacteria (Ehteshami et al., 2007; Wang et al., 2012). Co-inoculation of Rhizobium sp. and Pseudomonas sp. in Phaseolus vulgaris increased nodulation and growth parameters, compared to single inoculation (Sánchez et al., 2014). Chickpea inoculated with a consortium formulated with Rhizobium sp. and Mesorhizobium ciceri also increased plant production and plant growth (Shahzad et al., 2014). The study of soybeans and common beans co-inoculated with Bradyrhizobium japonicum and Azospirillum brasilense revealed an increment in the yield (Hungria et al., 2013). Regarding to microbial consortia applied to maize plants, the inoculation of A. brasilense and Bacillus subtillis improved phosphorus uptake, plant development, and corn grain yield (Pereira et al., 2020) Similarly, the consortium of Trichoderma harzianum OMG16 and B. amyloliquefaciens FZB42 increased the shoot dry matter and grain yield in maize (Mpanga et al., 2019).

In addition, the inoculation of plants with a PGPR consortium improved plant tolerance to abiotic stresses such as water deficit (Ehteshami et al., 2007; Wang et al., 2012; Shahzad et al., 2014), the tolerance to high salt concentration (Ahmad et al., 2013), and the high concentrations of heavy metals (Sheng et al., 2012; Hassan et al., 2014). Decreased application of chemical fertilization together with a good crop yield has been reported in plants inoculated with a bacterial consortium (Da Costa et al., 2013; Shahzad et al., 2013).

Traditional agricultural practices are based on the application of chemical fertilization to obtain high crop yields (Marks et al., 2013). However, the ecological costs generated by the massive application of chemical fertilizers are high, such as the contamination of agricultural soils, water, and the air with significant production of greenhouse gases (Marks et al., 2013; Coskun et al., 2017) and health damage to farmers (Hansen and Donohoe, 2003). Therefore, current agricultural practices require the adoption of new alternatives allowing high yields to be obtained with decreases in the pollutants generated by nitrogen fertilization (Hungria et al., 2013; Vacheron et al., 2013). In this context, P. vulgaris inoculated with selected microbial consortia showed an increment in fruit production with respect to the control, when plants were treated with $75 \%$ of chemical fertilization; similar grain yield and plant growth were obtained in treatments added with $100 \%$ of chemical fertilization (Chauhan and Bagyaraj, 2015). The co-inoculation of A. brasilense and B. subtilis in sugarcane (variety RB92579) growing in a field a $75 \%$ reduction in phosphorus fertilization increased the dry matter content, total phosphorus accumulation, and the production of stems by $38 \%$ (Rosa et al., 2020).

The beneficial effects on plants (plant growth and yield) inoculated with bacterial formulations (individual strains or in a consortium) could be affected by several factors, such as the bacterial genotype used for the formulation and the plant variety. These factors have been reported to play a role in sugarcane (Muñoz-Rojas and Caballero-Mellado, 2003; De Oliveira et al., 2006), corn (Mrkovački et al., 2016), tomato (Vaikuntapu et al., 2014), and bean (Sánchez et al., 2014). The analysis of several studies suggests that three key steps are required to achieve the beneficial effect of bacteria on plants: attraction of PGPR to a host plant, root colonization, and functional associative symbiosis (Drogue et al., 2012). Therefore, those steps must also be evaluated for consortium formulations (Molina-Romero et al., 2017).

Furthermore, PGPR used to formulate individual inoculants or consortia must be harmless, and they should be safe to human and animal health (Vílchez et al., 2015). The literature suggests the use of rhizobacteria classified as nonpathogenic (BSL-1), to design beneficial bacterial formulations for field application. In the case of BSL-2 microorganisms (pathogens and opportunistic pathogens), it is recommended to carry out experiment under strict containment and regulatory practices. However, applications of these microorganisms are not recommended (Keswani et al., 2019).

In our previous work (Molina-Romero et al., 2017), bacterial antagonism assays were performed among 20 strains using the double layer agar plate method. Using data on compatibility and desiccation resistance, a consortium formulated with four plant growth-promoting rhizobacteria (A. brasilense Sp7, $P$. putida KT2440, Acinetobacter sp. EMM02, Sphingomonas sp. OF178A) was designed. The compatibility of the selected strains for the bacterial consortium was verified under different growing conditions. All of strains were able to coexist and adapt under different environmental conditions. In addition, the strains of the consortium were experimentally evaluated for their capability to stimulate the growth of maize and their PGPR characteristics (Molina-Romero et al., 2017). P. putida KT2440, Acinetobacter sp. EMMS02, Sphingomonas sp. OF-178A, and the consortium displayed a high production of siderophores; $P$. putida KT2440, Acinetobacter sp. EMM02, and the consortium showed the highest phosphate solubilisation capacity; and A. brasilense Sp7 
and Acinetobacter sp. EMM02 presented the highest production of total indole compounds (Molina-Romero et al., 2017). Those observed characteristics were in line with other studies (Gamalero et al., 2004; Gulati et al., 2009; Planchamp et al., 2014; Rojas-Tapias et al., 2014; Lin et al., 2018; Bharwad and Rajkumar, 2020).

This consortium showed a beneficial effect on autochthonous blue maize. The benefits remained after subjecting the bacterial consortium to desiccation stress prior to the plant inoculation (Molina-Romero et al., 2017). However, this consortium has not been explored in other maize varieties or under field conditions.

This research aimed to evaluate the capability of $A$. brasilense Sp7, P. putida KT2440, Acinetobacter sp. EMM02, and Sphingomonas sp. OF178A (alone or in a consortium) to interact and stimulate the plant growth of 6 maize varieties, under greenhouse conditions. We selected the most promising maize variety for field application. This variety was again inoculated with the consortium and its capability to promote the plant growth was tested under field conditions, using different treatments of urea fertilization (50 and $100 \%$ of the recommended $\mathrm{N}$ dose). In addition, the effects of the oral administration of all PGPR used to formulate the consortium were evaluated in adult male Long Evans rats.

\section{MATERIALS AND METHODS}

\section{Germination Rate}

Fifty seeds of different maize varieties were inoculated using a bacterial mixture formulated as described previously (MolinaRomero et al., 2017). The maize varieties used were two autochthonous (yellow and red from the Huejotzingo region) and four hybrids (1463, 1069, 888, and H48), and hybrid varieties were coated with the carboxin-thiram fungicide (Abati et al., 2014; Haghanifar et al., 2018) by providers from the municipality of Huejotzingo. Inoculation was performed during $1 \mathrm{~h}$ by submerging seeds in the bacterial suspension containing $10^{7}$ Colony Forming Units (CFU)/mL of $A$. brasilense Sp7, $P$. putida KT2440, Acinetobacter sp. EMM02, Sphingomonas sp. OF178. After inoculation, seeds were placed on sterile filter paper moistened with sterile water deposited in a sterile petri dish and placed at $20^{\circ} \mathrm{C}$ for $48-72 \mathrm{~h}$ for germination. For the control treatment of each corn variety, seeds were submerged in distilled water only.

\section{Adherence and Colonization}

The cell suspension was prepared as described by MolinaRomero et al. (2017). Inoculation of autochthonous and hybrid seeds (coated with fungicide) was carried out by submerging them in the bacterial suspensions for $1 \mathrm{~h}$. The bacterial numbers of the suspension were determined in the order of $10^{6}$ to $10^{7}$ $\mathrm{CFU} / \mathrm{mL}$ by using the Massive Seal Drop Plate (MSDP) method (Corral-Lugo et al., 2012), selection media were used for each strain, determining the population for the individual strains and the bacterial consortium.

Fifty seeds of each variety (autochthonous or hybrid) were inoculated for $1 \mathrm{~h}$ with the respective bacterial suspension (single strains or the consortium). Inoculated seeds were sown in $50 \mathrm{~mL}$ conical tubes with $15 \mathrm{~g}$ of sterile vermiculite. Five milliliters of sterile MS liquid and $2 \mathrm{~mL}$ of water was added to each tube (Murashige and Skoog, 1962). All tubes were placed in a greenhouse with $16 \mathrm{~h}$ of light and a temperature of $30^{\circ} \mathrm{C}$ during the day and $8 \mathrm{~h}$ of darkness and a temperature of $25^{\circ} \mathrm{C}$ during the night.

Six inoculated seeds were extracted within $24 \mathrm{~h}$ of sowing and the bacterial number adhered to seeds was determined by the MSDP method. For this, seeds were placed in $50 \mathrm{~mL}$ conical tubes with $3 \mathrm{~mL}$ of sterile water for $1.5 \mathrm{~h}$. Selective media for each bacterial strain and the bacterial consortium were used for quantification (Molina-Romero et al., 2017). Plates were incubated for 24 to $48 \mathrm{~h}$ at $30^{\circ} \mathrm{C}$. The other inoculated seeds (with an individual bacterium or in a consortium) sown in sterile vermiculite were kept under greenhouse conditions for 21 days. Plants were watered with distilled water every 4 days. At 21 days post inoculation (dpi), six plants of each treatment were used to determine rhizosphere colonization (RodríguezAndrade et al., 2015). The root of each plant was placed in $50 \mathrm{~mL}$ conical tubes with $10 \mathrm{~mL}$ of sterile water for $1.5 \mathrm{~h}$. To determine the bacterial population extracted from the roots, the MSDP technique was used with each selection media for each bacterium; the incubation conditions of the plates were 24 to $48 \mathrm{~h}$ at $30^{\circ} \mathrm{C}$ (Rodríguez-Andrade et al., 2015; Molina-Romero et al., 2017). The vermiculite strongly adhered to the root was removed and its dry weight determined to calculate the parameter ColonyForming Units / gram of Vermiculite (CFU/gV) (Morales-García et al., 2011; Rodríguez-Andrade et al., 2015; Molina-Romero et al., 2017; Pazos-Rojas et al., 2019).

Some isolated bacteria were selected to confirm bacterial identity. To do it, the $16 \mathrm{~S}$ rDNA gene was amplified. The $1.5 \mathrm{~kb}$ amplifications were digested with the MspI enzyme; subsequently, the electrophoretic separation was performed to observe the characteristic restriction pattern of the PGPR inoculated in each plant (Molina-Romero et al., 2017).

\section{Animal Experiments}

Adult male Long Evans rats (with an average weight of 250 to $270 \mathrm{~g}$ ) were obtained from the Benemérita Universidad Autónoma de Puebla, México. The animals were housed in experimental cages; food and tap water were free to demand. Environmental conditions were maintained at a temperature of $22^{\circ} \mathrm{C} \pm 2{ }^{\circ} \mathrm{C}$ and $60 \%$ relative humidity, with a light-dark cycle of $12 \mathrm{~h}$. The protocol in this study was carried out according to the official Mexican standard NOM-062-ZOO-1999.

The treatments established to evaluate the PGPR-rat interaction were five (bacterial consortium and the four independent strains: A. brasilense Sp7, P. putida KT2440, Acinetobacter sp. EMM02, and Sphingomonas sp. OF178). For the control treatment, animals were not inoculated. Four animals were inoculated for each treatment ( $n=4$ rats).

Rats were dewormed and vitaminized before inoculation. A cell suspension of each strain and consortium was formulated with a population of $1 \times 10^{7} \mathrm{CFU} / \mathrm{mL}$, according to MolinaRomero et al. (2017). The administration of $1 \mathrm{~mL}$ of cell suspension was orally introduced with a cannula, after the sedation of the animal with phenobarbital ( $0.7 \mathrm{~mL} / 270 \mathrm{~g}$ weight). 
Animals of the control treatment were administered with $1 \mathrm{~mL}$ of physiological solution. Both inoculated and control rats were observed twice, every day, over a period of 30 days. Two independent experiments were established. The parameters evaluated in the rats were the alteration of motor activity, weight loss, diarrhea, and the presence of lethargy. In the presence of the aforementioned parameters and other symptoms that compromise the life of the animal, the slaughter would take place.

At the end of the evaluation time of the symptoms of bacterial infection (1 month), the rats were sedated and sacrificed by decapitation. The extraction of the meninges, small intestine, and a blood sample from the heart, under aseptic conditions, was performed. Organs and samples were homogenized with a physiological solution for subsequent seeding in the selection media designed for each PGPR (Molina-Romero et al., 2017). The incubation conditions of the selection media inoculated with the samples from the rats of each treatment were $48 \mathrm{~h}$ and $30^{\circ} \mathrm{C}$. The procedures described in this study were based on the Standards for the use and care of laboratory animals of the Mexican Council of Animal Care and as indicated in NOM-062-ZOO-1999, which are also approved by the Animals and Ethics Committee of the BUAP. All effort was made to minimize the number of animals used and to ensure minimal pain and discomfort.

\section{Determination of Growth Promotion Parameters Under Greenhouse}

Fifty seeds were inoculated for each treatment and were sown in pots containing $650 \mathrm{~g}$ of sterile vermiculite. Irrigation for each pot was done with 500 milliliters of sterile MS nutrient solution (Murashige and Skoog, 1962) and $200 \mathrm{~mL}$ of sterile water. The greenhouse cultivation conditions were $16 \mathrm{~h}$ of light at $30^{\circ} \mathrm{C}$ during the day and $8 \mathrm{~h}$ of darkened at $22^{\circ} \mathrm{C}$ during the night. Seedlings were developed up to $45 \mathrm{dpi}$ with regular irrigation with distilled water.

At 45 days after inoculation (dpi) plants were removed from the vermiculite and washed with water, and the excess water was dried with absorbent paper. A tape measure and Vernier were used to measure the height of the plant and the stem diameter, respectively. The fresh weight of the seedlings was determined with the analytical balance. Subsequently, the samples were dried in the oven at $75^{\circ} \mathrm{C}$ until they reached a constant weight. This procedure was also carried out to determine the growth parameters in the field experiment.

\section{Field Experiment}

\section{Localization of the Field Experiment}

The field experiment was carried out in the summer of 2015. The experiment was carried out in the municipality of Huejotzingo, Puebla México, located between $19^{\circ} 06^{\prime}$ and $19^{\circ} 16^{\prime}$ in north latitude; $98^{\circ} 20^{\prime}$ and $98^{\circ} 38^{\prime}$ in west longitude meridians. The climate is temperate sub-humid with rains in summer, with an average maximum temperature of $16^{\circ} \mathrm{C}$ and a minimum of $2^{\circ} \mathrm{C}$. The average annual precipitation is 900 to $1,100 \mathrm{~mm}$ in the territory. Physicochemical analysis of a soil sample from the experimental place was determined as sandy clay soil, according to standard methods (Shahzad et al., 2014).

\section{Treatments and Experimental Design}

Four treatments were established in the field: (1) Bacterial consortium treatment; seeds inoculated with the consortium alone, without urea application in the field. (2) Urea treatment; seeds without bacterial inoculation with a complete dose of urea fertilization (100\%) in the field. (3) $50 \%$ urea treatment plus consortium; seeds inoculated with the consortium and half dose of urea fertilization applied in the field. (4) Control treatment, non-inoculated seeds without urea application in the field.

The seeds (from the bacterial consortium and 50\% urea plus consortium treatments) were inoculated as previously described in the adherence and colonization section. The seeds of the control treatment and $100 \%$ urea were immersed in sterile distilled water for $1 \mathrm{~h}$ to discard the effect of water. The seeds were sown manually in plots $(0.8 \mathrm{~m}$ wide by $152 \mathrm{~m}$ long, with 8 replicates for each treatment) with a distance from plant to plant of $80 \mathrm{~cm}$.

Nitrogen chemical fertilization was applied using the commercial urea formula (46-0-0) in only two treatments: $100 \%$ urea $(69 \mathrm{~kg}$ of $\mathrm{N} / \mathrm{ha}$ ) and $50 \%$ urea $(34.5 \mathrm{~kg}$ of $\mathrm{N} / \mathrm{ha})$ plus consortium treatments. For the irrigation in the temporary field, a water channel was used.

The design employed was randomized complete block design (RCBD) with four treatments and 8 replicates, the experimental area was divided into $973 \mathrm{~m}^{2}$ for each treatment. The plot was separated by $1.0 \mathrm{~m}$, with small furrows of approximately $1.5 \mathrm{~m}$ to prevent surface mixing with the bacteria and fertilizer used in each treatment. This is because of the strong rains that are common in the summer season.

\section{Recording of Growth Parameters and Production}

The corn growth period was carried out in the traditional period season from March to June 2016. Growth parameters (plant height, root dry weight, root length, and plant diameter) were evaluated using 20 plants of each treatment, through the design of random blocks. The plant growth parameters were recorded for 80 days after sowing as previously described in the methodology of the greenhouse experiment.

Biomass and production were recorded after the maturity of the crop, 190 days after sowing, the corn was harvested and the cobs were separated, later they were weighed on a balance; the data were converted to $\mathrm{Kg} / \mathrm{ha}$, following the unit method.

\section{Statistical Analysis}

Data on plants (adherence, colonization, and growth parameters) were subjected to a one-way analysis of variance (ANOVA). Significant differences between average were obtained with Duncan multiple range test at $P \leq 0.05$, using SigmaPlot 12 (Handel Scientific Software).

\section{RESULTS}

\section{Germination of Maize Inoculated With a Bacterial Consortium}

The percentage of germination in both yellow and red autochthonous maize varieties with and without bacterial 


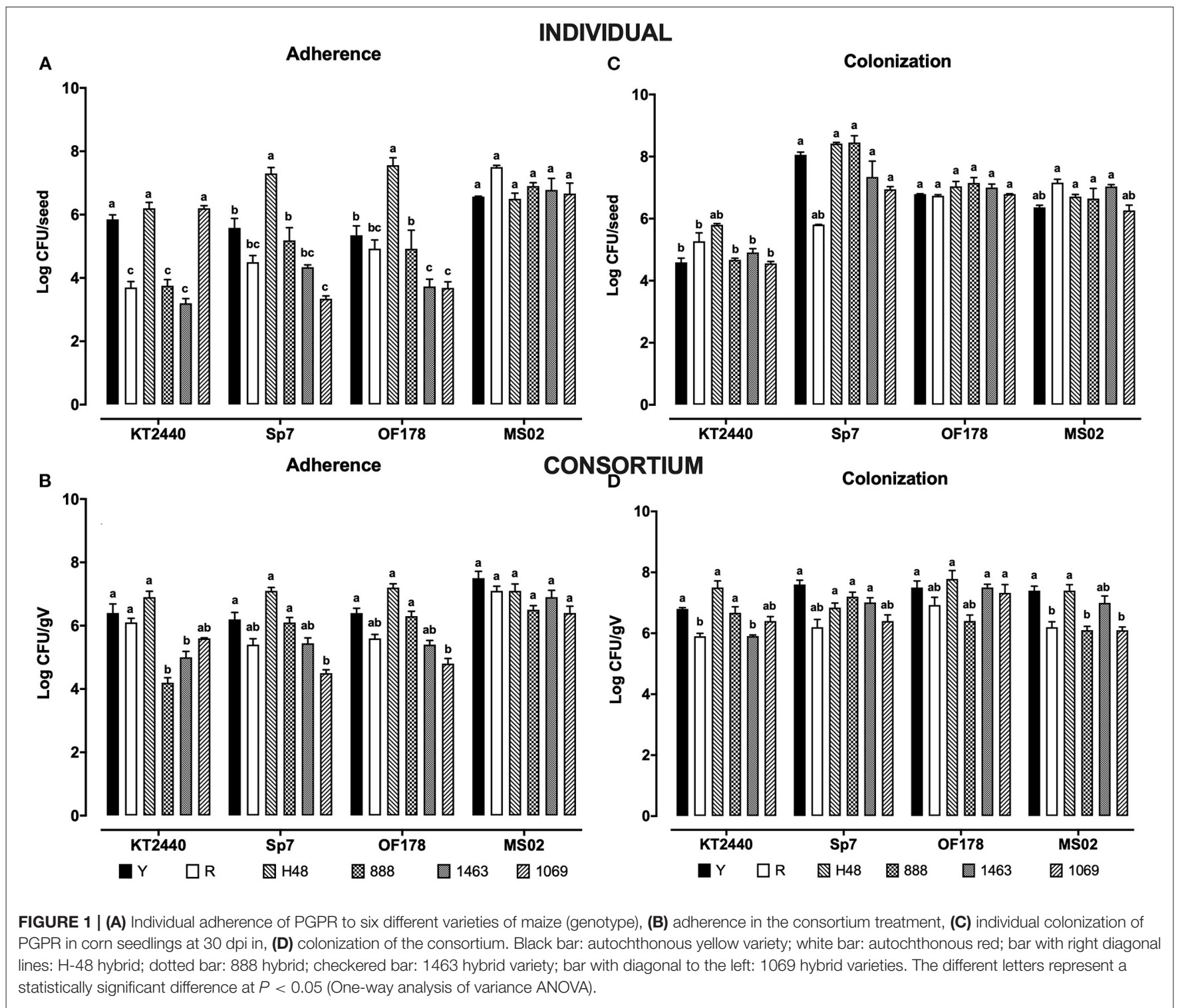

inoculation was of $100 \%$. All hybrid varieties showed a germination percentage of $100 \%$ when they were inoculated with the bacterial consortium. In contrast, the non-inoculated seeds of 1069 and 1463 hybrids varieties presented 96\% germination. The H48 and 888 hybrids presented 98 and 100\% of germination, respectively.

\section{Adherence}

The four strains (alone or in a consortium) had the ability to adhere to the six maize seed varieties under in vitro conditions. The individual adhesion of Acinetobacter sp. MS02 presented a similar trend in all varieties explored, on the order of $10^{6}-10^{7} \mathrm{CFU} / \mathrm{seed}$ (Figure 1A). The adhesion of this strain increased one order of magnitude, in the autochthonous yellow and the hybrid $\mathrm{H} 48$ varieties, when it was inoculated in a consortium (Figure 1B). However, in the hybrids varieties (888, 1463 , and 1069) and the red autochthonous variety, adhesion maintained the same tendency when the bacteria were inoculated individually or in a consortium.

A. brasilense Sp7 and Sphingomonas sp. OF178 had a similar adhesion capability in most varieties explored. They adhered at high numbers $\left(10^{5}-10^{7} \mathrm{CFU} / \mathrm{seed}\right)$ to the yellow autochthonous variety, and to the hybrid varieties $\mathrm{H} 48$ and 888. However, they adhered at low numbers $\left(10^{3}-10^{4} \mathrm{CFU} / \mathrm{seed}\right)$ to the red autochthonous variety and the hybrid varieties 1069 and 1463 (Figure 1A).

The adhesion of $P$. putida KT2440 to the autochthonous red variety, and the 888 and 1463 hybrids was lower, with bacterial numbers on the order of $10^{3} \mathrm{CFU} /$ seed. However, KT2440 showed a high adhesion in the H48, 1069, and yellow autochthonous varieties $\left(10^{5}-10^{6} \mathrm{CFU} /\right.$ seed $)$.

Interestingly, $A$. brasilense Sp7, P. putida KT2440, and Sphingomonas sp. OF178 inoculated in a consortium, showed an increased adhesion (one or two orders of magnitude) (Figure 1B) 
compared to their individual adhesion in hybrid varieties 888 , 1463 , and 1069, and the autochthonous yellow and red varieties (Figure 1B). For the H48 hybrid, adhesion of the bacterial strains remained similar under individual or consortium inoculation $\left(10^{7} \mathrm{CFU} /\right.$ seed).

\section{Rhizosphere Colonization}

Sphingomonas sp. OF178 and Acinetobacter sp. MS02 showed a similar rhizosphere colonization in the six corn varieties, $10^{6}-10^{7}$ $\mathrm{CFU} / \mathrm{gV}$ and $10^{5}$ to $10^{6} \mathrm{CFU} / \mathrm{gV}$, respectively (Figure 1C).

In the yellow autochthonous variety, and the H48 and 888 hybrids, A brasilense Sp7 presented a higher individual colonization $\left(10^{8} \mathrm{CFU} / \mathrm{gV}\right)$ (Figure 1C) than was observed in the red autochthonous variety and 1463 and 1069 hybrids $\left(10^{6} \mathrm{CFU} / \mathrm{gV}\right)$.

The low individual colonization of $P$. putida KT2440 $\left(10^{4}\right.$ to $10^{5} \mathrm{CFU} / \mathrm{gV}$ ) was observed in the autochthonous and hybrid varieties (Figure 1C).

The colonization of A. brasilense Sp7, Sphingomonas sp. OF178, and Acinetobacter sp. MS02 strains in the consortium showed a rhizosphere colonization ranging from $10^{6}$ to $10^{7}$ $\mathrm{CFU} / \mathrm{gV}$, for all tested varieties (Figure 1D). In several cases, bacterial colonization in the consortium was increased. The rhizosphere colonization of $P$. putida KT2440 increased in the consortium inoculation treatments, in most of maize varieties evaluated, with the exception of the autochthonous red variety, in which the colonization remained similar to individual rhizosphere colonization (Figure 1D).

\section{Interaction Tests of PGPR With the Rat Animal Model}

The effect of PGPR inoculation on the rat model was evaluated. The rats inoculated with A. brasilense Sp7, P. putida KT2440, Acinetobacter sp. EMM02, Sphingomonas sp. OF178A, or the bacterial consortium did not show any changes in their motor activity, and there was not weight loss or lethargy observed from the time of inoculation until 30 days after inoculation (Table 1). Therefore, rats inoculated with the bacterial consortium or individual treatments did not exhibit any alterations, indicating that there was no damage to their health. Interestingly, bacteria were undetectable, in blood, meninges, and small intestine samples from rats treated with the bacterial consortium or individual strains (Table 1).

\section{Effect of Consortium Inoculation on Growth Promotion in the H48 Hybrid and Yellow Autochthonous Varieties Under Greenhouse Conditions}

The bacterial consortium showed an adequate capacity to adhere to and colonize the seeds of the H48 hybrid and yellow autochthonous varieties. The adherence was $10^{6}$ to $10^{7}$ $\mathrm{CFU} /$ seed, and colonization rate was $10^{6}$ to $10^{7} \mathrm{CFU} / \mathrm{gV}$ in the two varieties. Likewise, when the seeds of these two varieties were inoculated with the four PGPR strains individually, they presented similar adherence and colonization.
Based on these results, the H48 hybrid and autochthonous yellow varieties were inoculated with the bacterial consortium to evaluate whether the consortium promotes plant growth under greenhouse conditions.

The dry weight of the aerial parts of the H48 hybrid plants inoculated with the bacterial consortium was $7.23 \mathrm{~g}( \pm 0.81)$, and it was $5.62 \mathrm{~g}( \pm 0.58)$ for control plants. The difference was significant statistically ( $p \leq 0.05$ ) (Figure $2 \mathrm{E}$ ). The dry weight of the aerial part of the autochthonous yellow variety inoculated with the consortium $(5.43 \mathrm{~g} \pm 0.38)$ was significantly higher than that of the control plants $4.08 \mathrm{~g}( \pm 0.55)$ (Figure 2A).

The root dry weight of both varieties inoculated with the consortium was significantly higher $(5.33 \mathrm{~g}$ for $\mathrm{H} 48$ and $3.04 \mathrm{~g}$ for indigenous yellow) than that of the control plants (3.82 and $1.87 \mathrm{~g}$, respectively) (Figures 2B,F).

Likewise, the H48 hybrid and indigenous yellow varieties inoculated with the consortium surpassed the control treatment in the parameters of height and diameter, with a significant difference (Figures 2C,D, G,H).

\section{Autochthonous Yellow Variety Under Field Conditions}

The native yellow maize was the variety showing the most stimulation after the inoculation of the bacterial consortium, under greenhouse conditions. Also, this variety is of great interest to farmers in the region Huejotzingo region of Puebla, because they prefer to cultivate indigenous corn varieties. Therefore, we decided to evaluate the effect of bacterial inoculation on the autochthonous yellow variety under field conditions.

The results of the field experiment showed that treatments with bacterial inoculation increased the plant height, dry root weight, and root length of the yellow variety compared to the control plants.

Plants subjected to the $50 \%$ urea plus consortium treatment and the plants fertilized with $100 \%$ urea presented the higher values of plant height, root dry weight, root length, and plant diameter. In general, parameters of growth between these two treatments were not significantly different (Table 2A).

The height, root length, and dry weight of the plants inoculated with the consortium compared to the controls showed significantly higher values: 204.62 and $184.63 \mathrm{~cm}$ of plant height, 36.28 and $33.38 \mathrm{~cm}$ root length; and 7.33 and $6.11 \mathrm{~g}$ of dry weight, respectively (Table 2A). However, the diameter of the plants inoculated with the bacterial consortium was similar to the values recorded for the control plants, without any statistically significant differences (Table 2A).

The plants treated with $100 \%$ urea and the control plants showed the highest biomass production under field conditions. In contrast, the treatments resulting in the lowest biomass production included the plants inoculated with the bacterial consortium alone and plants treated with $50 \%$ urea plus the consortium (4.74 and $4.59 \mathrm{t} / \mathrm{ha}$, respectively) (Table 2B).

The $50 \%$ urea plus consortium treatment resulted in the highest grain yield, followed by the $100 \%$ urea treatment $(5353.50$ and $4914.50 \mathrm{~kg} / \mathrm{ha}$, respectively). In contrast, the bacterial consortium treatment resulted in the third highest in grain 
TABLE 1 | Effects of PGPR on the rat animal model.

\begin{tabular}{|c|c|c|c|c|c|c|c|}
\hline \multirow[t]{2}{*}{ Treatment } & \multirow[t]{2}{*}{ Motor activity } & \multirow[t]{2}{*}{ Lethargy } & \multirow[t]{2}{*}{ Weight loss of the animal } & \multirow[t]{2}{*}{ Animal sacrifice } & \multicolumn{3}{|c|}{ PGPR isolation, after oral inoculation } \\
\hline & & & & & Blood & Meninges & Small intestine \\
\hline Control & $\mathrm{N}$ & A & $\mathrm{N}$ & A & $\mathrm{NI}$ & $\mathrm{NI}$ & $\mathrm{NI}$ \\
\hline A. brasilense Sp7 & $N$ & A & $N$ & A & $\mathrm{NI}$ & $\mathrm{Nl}$ & $\mathrm{NI}$ \\
\hline P. putida KT2440 & $\mathrm{N}$ & A & $\mathrm{N}$ & A & $\mathrm{Nl}$ & $\mathrm{Nl}$ & $\mathrm{NI}$ \\
\hline Acinetobacter sp. EMM02 & $N$ & A & $N$ & A & $\mathrm{NI}$ & $\mathrm{NI}$ & $\mathrm{NI}$ \\
\hline Sphingomonas sp. OF178A & $\mathrm{N}$ & A & $N$ & A & $\mathrm{NI}$ & $\mathrm{NI}$ & $\mathrm{NI}$ \\
\hline Consortium & $\mathrm{N}$ & $A$ & $\mathrm{~N}$ & $A$ & $\mathrm{NI}$ & $\mathrm{NI}$ & $\mathrm{NI}$ \\
\hline
\end{tabular}

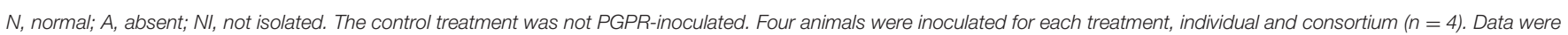
obtained from two independent experiments.

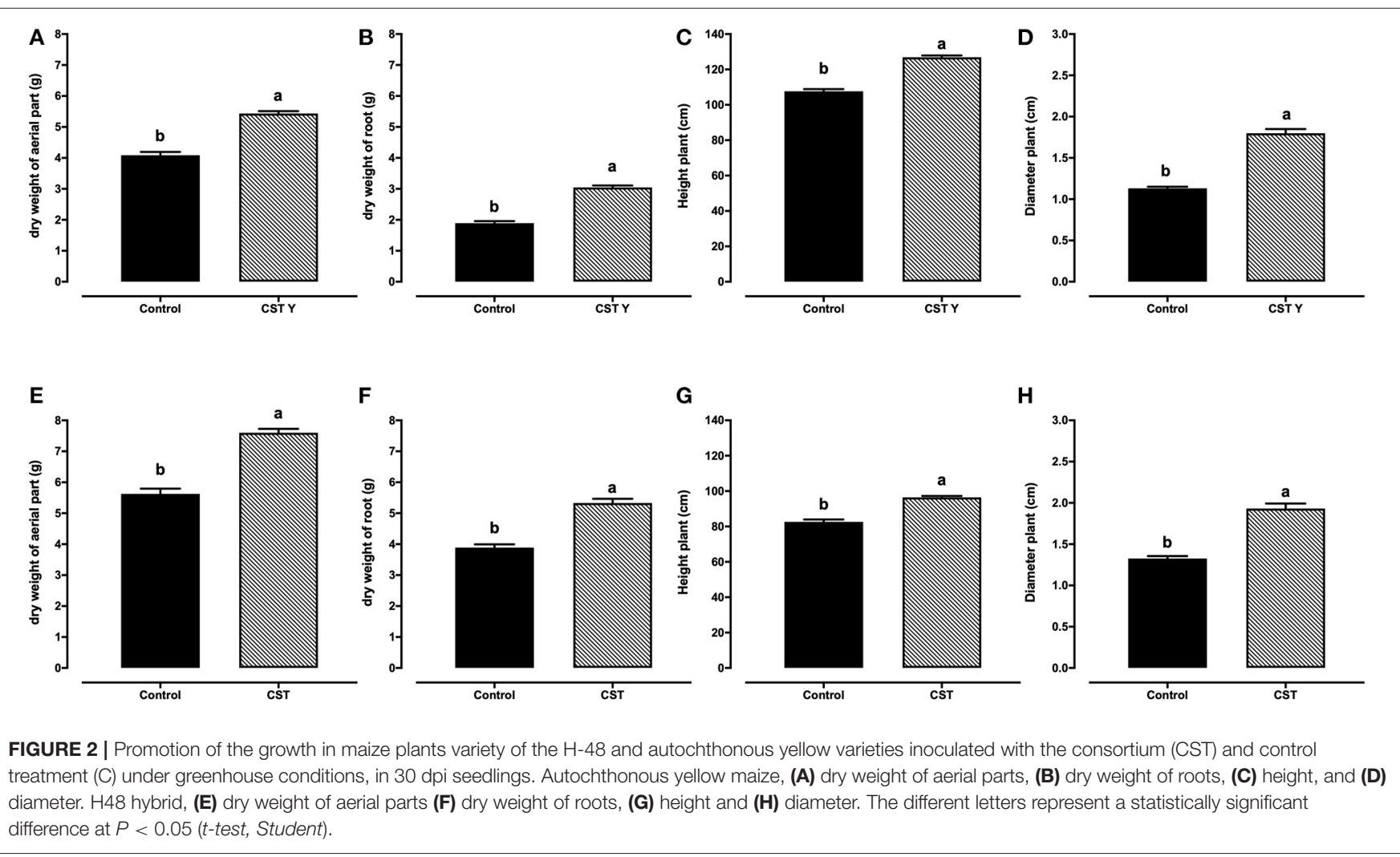

production; and the lowest production was presented by the control (4549.3 and $3916.0 \mathrm{~kg} / \mathrm{ha}$, respectively) (Table 2B).

An increase of $1437.5 \mathrm{~kg} / \mathrm{ha}$ was obtained with the $50 \%$ urea plus consortium treatment compared to the control (Table 2B).

\section{DISCUSSION}

Bacterial establishment in the rhizosphere is a crucial step to obtain the beneficial effect of PGPR on the host plant. Therefore, an adequate adhesion and colonization must occur to obtain the desired effects (Drogue et al., 2012; Shahzad et al., 2013). Individual and consortium bacterial adhesion to maize for $A$. brasilense Sp7, P. putida KT2440, Acinetobacter sp. EMM02, and Sphingomonas sp. OF178A was variable among the maize seed varieties explored in this work, suggesting differences in bacterium-seed affinity. It is important to highlight that the adhesion was improved when bacterial strains were applied in the consortium to all corn varieties used and was in agreement with our previous observations in the blue autochthonous variety (Molina-Romero et al., 2017).

A correlation between colonization capacity and the ability to stimulate plants has been reported (Moradtalab et al., 2020). For example, a colonization on the order of $10^{7} \mathrm{CFU} / \mathrm{g}$ root dry weight stimulates the plant biomass of the forage maize (Piromyou et al., 2011). In our work, the colonization following individual and bacterial consortium inoculation in the $888,1069,1463$, and red-autochthonous varieties was less efficient compared to that in the H48 and autochthonous yellow 
TABLE 2 | Effect of the consortium inoculation on the growth of autochthonous yellow maize under field conditions using different levels of urea fertilization.

\begin{tabular}{lcccc}
\hline (A) & & & & \\
Treatment & Plant Height $(\mathbf{c m})$ & Dry root weight (g) & Root Length (cm) & Plant diameter (cm) \\
\hline Control & $184.63 \pm 6.64 \mathrm{c}$ & $6.11 \pm 0.51 \mathrm{c}$ & $33.38 \pm 2.35 \mathrm{c}$ & $8.55 \pm 0.64 \mathrm{~b}$ \\
Consortium & $204.62 \pm 13.17 \mathrm{~b}$ & $7.33 \pm 0.74 \mathrm{~b}$ & $36.28 \pm 2.19 \mathrm{~b}$ & $9.55 \pm 0.73 \mathrm{ab}$ \\
Urea 100\% & $221.50 \pm 17.07 \mathrm{a}$ & $7.23 \pm 0.60 \mathrm{~b}$ & $40.28 \pm 2.39 \mathrm{a}$ & $10.32 \pm 0.89 \mathrm{a}$ \\
Urea 50\%+ consortium & $228.84 \pm 11.24 \mathrm{a}$ & $8.30 \pm 0.69 \mathrm{a}$ & $42.52 \pm 2.94 \mathrm{a}$ & $10.44 \pm 0.69 \mathrm{a}$ \\
\hline
\end{tabular}

(B)

Treatment

Total biomass $\mathrm{t} / \mathrm{ha}$

Control

Consortium

Urea $100 \%$

Urea $50 \%+$ consortium

$$
\begin{gathered}
5.10 \pm 2.4 a \\
4.74 \pm 1.6 a b \\
5.15 \pm 3.9 a \\
4.59 \pm 1.9 b
\end{gathered}
$$

Grain production $\mathrm{t} / \mathrm{ha}$

$$
\begin{gathered}
3.91 \pm 0.26 \mathrm{c} \\
4.54 \pm 0.24 \mathrm{~b} \\
4.91 \pm 0.25 \mathrm{ab} \\
5.35 \pm 0.15 \mathrm{a}
\end{gathered}
$$

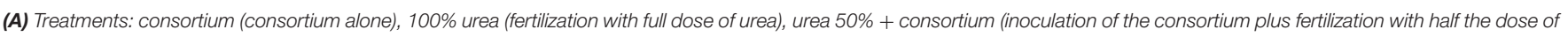

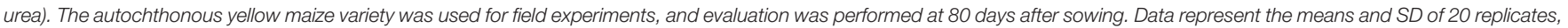

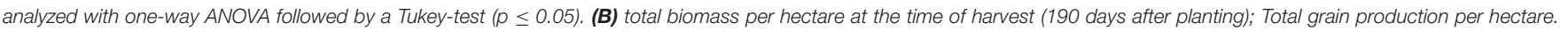

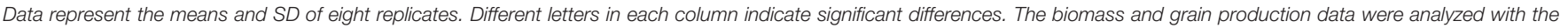
Duncan multiple range test at $p \leq 0.05$.

varieties. However, the inoculation of the bacterial consortium improved the bacterial colonization capacity compared to the individual treatments. However, a correlation between adequate colonization and the growth promotion of the plants of the H48 hybrid and autochthonous yellow varieties was observed.

Bacterial colonization depends on the plant variety. The colonization of a consortium formulated with Gluconacetobacter diazotrophicus, Herbaspirillum seropedicae, Herbaspirillum rubrisubalbicans, Azospirillum amazonense, and Burkholderia tropica was found to differ in two varieties of sugar cane (SP70-1143 and SP 813250) (De Oliveira et al., 2006). The colonization capability of other consortia (Pseudomonas striata and Piriformospora indica) is also plant-dependent in maize varieties or mung beans varieties (Singh et al., 2009). In the present study, we also observed the influence of the maize variety on the bacterial colonization.

Few studies have evaluated the microbiological safety of PGPR before field application. Bacterial strains used to improve plant growth must be safe for human health and the environment (Kampers et al., 2019; Visnovsky et al., 2020). An example in which bacterial innocuity was explored is provided by the work reported by Chávez-Ramírez et al. (2020) in Paenibacillus polimyxa (NMA1017), whose safety was tested on tobacco leaves and the Galleria mellonella larvae, reinforcing its safe application as a biocontrol agent (Chávez-Ramírez et al., 2020). In the present work, we used a rat model to explore whether the bacterial strains provoke adverse effects on the animals after the oral administration of $1 \mathrm{~mL}$ containing $10^{7} \mathrm{CFU} / \mathrm{mL}$. The absence of signs of disease and the lack of bacteria in the blood, meninges, and small intestines of the animals inoculated with the bacterial consortium or individual strains, suggested that the bacterial strains were innocuous to the rats and they could be safe for human health when applied to the crops.

It is important to verify the safety of PGPR before they are used as biofertilizers, especially if they are closely related to pathogenic bacterial strains. For example, Bacillus sp. (RZ2MS9) and Burkholderia ambifaria (RZ2MS16) present a potential risk due to their taxonomic proximity to pathogenic groups (Batista et al., 2018; Ferreira et al., 2019), especially when a formulation includes bacteria considered to be opportunistic pathogens, such as $P$. aeruginosa (Lavakush et al., 2014). By conducting this verification, we can ensure that the application in the field does not represent a health risk to people who are in contact with the formulation when it is applied to plants.

Regarding the plant growth promotion under greenhouse conditions, the autochthonous yellow variety and the H48 hybrid inoculated with the bacterial consortium showed significant increases in height, diameter, the dry weight of the aerial part and the roots compared to the control. The benefit to growth parameters was probably due to the ability of the bacteria of the consortium to produce indoles, solubilise phosphates, and produce siderophores (Molina-Romero et al., 2017). These beneficial effects agree with the previous observations made in blue maize inoculated with this same consortium (MolinaRomero et al., 2017). Similarly, an increase in root dry weight was recorded in jolly hybrid maize, when it was inoculated with a Bacillus subtilis FZB24 and B. subtilis GB03 consortium (Myresiotis et al., 2015). In contrast, a consortium of Azospirillum lipoferum, P. fluorescens, $P$. putida, and chitosan did not increase the height, diameter, or number of leaves per plant but significantly increased the dry weight of the roots and the aerial parts of the maize under greenhouse conditions (Agbodjato et al., 2016). The co-inoculation of maize with A. brasilense and $B$. subtillis has also shown greater benefits than individual inoculation (Pereira et al., 2020).

In the present fieldwork, the inoculation of the bacterial consortium in the autochthonous yellow variety produced a beneficial effect on the plants, increasing the height, dry root weight, and root length of the plant and yield. However, the total biomass and the diameter of the plants inoculated with 
the consortium were similar to the control. These growthpromotion results showed a trend similar to the trend reported in a field study indicating that the maize inoculation with a consortium with Azotobacter chrococcum and A. liporefum resulted in increments in shoot and seed dry weight, plant height, and yield compared to the individual inoculation of PGPR and the control (Biari et al., 2008).

In this study, nitrogen fertilization at $100 \%$ and the treatment with the consortium plus $50 \%$ urea resulted in the greatest increments in height, diameter, dry root weight, and grain production in comparison to non-inoculated plants. These results showed that the consortium stimulates the growth of autochthonous maize when a half dose of mineral nitrogen used in traditional Mexican agricultural practices is added, which generated results similar to the application of a complete nitrogen dose.

Similar trends have been reported in other studies. For example, the rice inoculation with a consortium (combined Pseudomonas culture, A. chroococcum, and A. brasilense) plus the application of $50 \%$ mineral phosphorus resulted in results similar to the complete dose of phosphorus plus the consortium (Lavakush et al., 2014). Additionally, the hybrid maize (33M15) has been inoculated with Pseudomonas thivervalensis (STF3) (Shahzad et al., 2013), the hybrid corn (786) has been inoculated with $P$. fluorescens biotype G (N3) (Naveed et al., 2008), and safflower has been inoculated with Azospirillum sp. and Azotobacter sp. (Nosheen et al., 2016). In sunflower, the highest grain production, oil, and protein content were observed in association with the consortium (Azotobacter sp. and Azospirillum sp.) plus 50\% nitrogen fertilization (Naseri and Mirzaei, 2010).

Most of the studies in which plants were inoculated with PGPR or consortia have reported an increase in yield and biomass (Ehteshami et al., 2007; Kumar et al., 2007; Shahzad et al., 2013). In this work a higher grain yield was observed following the application of the consortium plus 50\% urea while the biomass production was lower compared to the control, consortium inoculation alone, or $100 \%$ urea treatment. Most likely, during the interaction with bacteria, nutrients in the plant are directed to grain formation instead of other plant structures (Okuno et al., 2014), which should be clarified in the future. The results observed in maize inoculated with the consortium and treated a half of the dose of nitrogen fertilization contrasts with the direct correlation established between nutrition and higher grain production, particularly when abundant mineral nitrogen is available (Rozier et al., 2017; Bisht and Chauhan, 2020).

Plants interact with efficient indole-producing and phosphate solubilizing bacteria under low-nutrient conditions. However, in a moderate nutrient scheme, plants selectively associate with bacteria with a higher capacity for phosphate solubilization (Da Costa et al., 2013; Pii et al., 2019; Bisht and Chauhan, 2020). As observed in this work, under treatment with $50 \%$ urea plus the consortium, we registered a higher promotion of plant growth and grain production due to the beneficial effect of the consortium. This effect could be due to a high phosphate solubilization capability and indole production among the strains of the consortium (Molina-Romero et al., 2017). However, it is necessary to do more work addressing this topic, perhaps using mutants defective in these mechanisms to verify their roles in the interaction.

Under conditions of abundant nutrients, this selective interaction with bacteria is abolished (Da Costa et al., 2013; Di Salvo et al., 2018), showing that fertilization affects the PGPRplant interaction. More work is required to define the role of bacterial mixtures on plant inoculation under field conditions. However, the eco-friendly technologies for increasing crop yields are promising (Morales-García et al., 2019).

The application of consortia in agricultural practice is offered as an alternative to implementing sustainable agriculture practices (García De Salamone et al., 2010), due to the reduction of chemical fertilization without compromising the grain yield (Tilman et al., 2002). Only 50\% of nitrogen fertilizer applied into the field is absorbed by plants; the remaining half is lost to the environment in the form of ammonia, nitrate, and nitrous oxide, contributing to the pollution of soil, water, and air and to climate change (Coskun et al., 2017; Schröder et al., 2018). Increasing the application of mineral nitrogen fertilizer in rice, corn, wheat, and barley can increase methane and nitrous oxide emissions from agriculture, which directly impacts global warming, due to the characteristics of methane and nitrous oxide as greenhouse gases (Bodelier et al., 2000; Good and Beatty, 2011).

The bacterial consortium studied in this work presents the characteristics of biofertilizer: inducing efficient interaction with the plant, and ecological nature, and contributions to lowering the costs of maize production due to the reduced of mineral nitrogen requirement. Consequently, a decrease in diminution of pollution caused by nitrogen fertilization occurs. Furthermore, the consortium is safe to handle when applied under field conditions.

\section{CONCLUSION}

This research presents the potential of a second-generation consortium formulated with A. brasilense Sp7, P. putida KT2440, Acinetobacter sp. EMM02, and Sphingomonas sp. OF178A. The bacterial strains of the consortium are compatible, resistant to desiccation, and efficient for field applications. Since the bacteria of this consortium interact efficiently with the autochthonous yellow maize variety, they trigger a beneficial effect on the grain yield. In addition, this bacterial consortium offers an alternative allowing the efficient use of half the recommended amount of nitrogen fertilizer. The use of the consortium allows a $50 \%$ reduction in mineral nitrogen application and generates important benefits for agricultural practices such as lower costs to the producer and a significant decrease in environmental pollution. Based on the results of the animal model, we suggest that the bacterial consortium is a safe formulation for use and manipulation under field conditions and does not cause health problems to animals.

\section{DATA AVAILABILITY STATEMENT}

The original contributions presented in the study are included in the article/supplementary materials, further inquiries can be directed to the corresponding author/s. 


\section{ETHICS STATEMENT}

The experiments with animals were carried out in strict accordance with the Mexican Law of Animal Treatment and Protection Guidelines. The animal study was reviewed and approved by Committee of Benemerita Universidad Autonoma de Puebla.

\section{AUTHOR CONTRIBUTIONS}

BV, YM-G, and JM-R: data curation. DM-R and YM-G: funding acquisition. BV, DM-R, and JM-R: research. SJ-S, CO-G, and DM-R: methodology. SJ-S and CO-G: resources. $\mathrm{BV}, \mathrm{AB}$, and DM-R: software. JM-R: supervisión. $A B$, YM-G, and DM-R: writing-original draft. DM-R,

\section{REFERENCES}

Abati, J., Zucareli, C., Foloni, J. S. S., Henning, F. A., Brzezinski, C. R., and Henning, A. A. (2014). Treatment with fungicides and insecticides on the physiological quality and health of wheat seeds. J. Seed Sci. 36, 392-398. doi: 10.1590/2317-1545v36n41006

Adjanohoun, A., Allagbe, M., Noumavo, P. A., Gotoechan-Hodonou, H., Sikirou, R., Dossa, K. K., et al. (2011). Effects of plant growth promoting rhizobacteria on field grown maize. J. Anim. Plant Sci. 11, 1457-1465.

Agbodjato, N. A., Noumavo, P. A., Adjanohoun, A., Agbessi, L., and BabaMoussa, L. (2016). Synergistic effects of plant growth promoting rhizobacteria and chitosan on in vitro seeds germination, greenhouse growth, and nutrient uptake of maize (Zea mays L.). Biotechnol. Res. Int. 2016:7830182. doi: 10.1155/2016/7830182

Ahmad, M., Zahir, Z. A., Khalid, M., Nazli, F., and Arshad, M. (2013). Efficacy of Rhizobium and Pseudomonas strains to improve physiology, ionic balance and quality of mung bean under salt-affected conditions on farmer's fields. Plant Physiol. Biochem. 63, 170-176. doi: 10.1016/j.plaphy.2012.11.024

Batista, B. D., Lacava, P. T., Ferrari, A., Teixeira-Silva, N. S., Bonatelli, M. L., Tsui, S., et al. (2018). Screening of tropically derived, multi-trait plant growthpromoting rhizobacteria and evaluation of corn and soybean colonization ability. Microbiol. Res. 206, 33-42. doi: 10.1016/j.micres.2017.09.007

Bharwad, K., and Rajkumar, S. (2020). Modulation of PQQ-dependent glucose dehydrogenase (mGDH and $\mathrm{sGDH}$ ) activity by succinate in phosphate solubilizing plant growth promoting Acinetobacter sp. SK2. 3 Biotech 10:15. doi: 10.1007/s13205-019-1991-2

Biari, A., and G., and, H.,A, A.R. (2008). Growth promotion and enhanced nutrient uptake of maize (Zea mays L.) by application of plant growth promoting rhizobacteria in arid region of Iran. J. Biol. Sci. 8, 1015-1020. doi: $10.3923 /$ jbs.2008.1015.1020

Bisht, N., and Chauhan, P. S. (2020). Comparing the growth-promoting potential of Paenibacillus lentimorbus and Bacillus amyloliquefaciens in Oryza sativa L. var. Sarju-52 under suboptimal nutrient conditions. Plant Physiol. Biochem. 146, 187-197. doi: 10.1016/j.plaphy.2019.11.023

Bodelier, P. L., Roslev, P., Henckel, T., and Frenzel, P. (2000). Stimulation by ammonium-based fertilizers of methane oxidation in soil around rice roots. Nature 403, 421-424. doi: 10.1038/35000193

Chauhan, H., and Bagyaraj, D. J. (2015). Inoculation with selected microbial consortia not only enhances growth and yield of French bean but also reduces fertilizer application under field condition. Sci. Horticul. 197, 441-446. doi: 10.1016/j.scienta.2015.10.001

Chávez-Ramírez, B., Kerber-Díaz, J. C., Acoltzi-Conde, M. C., Ibarra, J. A., Vásquez-Murrieta, M. S., and Estrada-De Los Santos, P. (2020). Inhibition of Rhizoctonia solani RhCh-14 and Pythium ultimum PyFr-14 by Paenibacillus polymyxa NMA1017 and Burkholderia cenocepacia CACua-24: a proposal for biocontrol of phytopathogenic fungi. Microbiol. Res. 230:126347. doi: 10.1016/j.micres.2019.126347
$A B$, and JM-R: writing-review and editing. All authors have read and agree to the published version of the manuscript.

\section{FUNDING}

Funding was provided by the intramural program of the Vicerrectoria de Investigación y Estudios de Posgrado, BUAP through grants VIEP-BUAP-2019 (00685 and 00527).

\section{ACKNOWLEDGMENTS}

The authors want to thank the SJ-S family for their support in the loan of the farmland for the development of the experiment in the field.

Corral-Lugo, A., Morales-García, Y. E., Pazos-Rojas, L. A., Ramírez-Valverde, A., Martínez-Contreras, D. R., J., et al. (2012). Cuantificación de bacterias cultivables mediante el método de "Goteo en Placa por Sellado (o estampado) Masivo. Rev. Colombiana Biotecnol. 14, 147-156. Available online at: https:// dialnet.unirioja.es/servlet/articulo? codigo $=4194978$

Coskun, D., Britto, D. T., Shi, W., and Kronzucker, H. J. (2017). Nitrogen transformations in modern agriculture and the role of biological nitrification inhibition. Nat Plants 3:17074. doi: 10.1038/nplants.2017.74

Da Costa, P. B., Beneduzi, A., De Souza, R., Schoenfeld, R., Vargas, L. K., and Passaglia, L. M. P. (2013). The effects of different fertilization conditions on bacterial plant growth promoting traits: guidelines for directed bacterial prospection and testing. Plant Soil 368, 267-280. doi: 10.1007/s11104-012-1513-z

De Oliveira, A. L. M., De Canuto, E. L., Urquiaga, S., Reis, V. M., and Baldani, J. I. (2006). Yield of micropropagated sugarcane varieties in different soil types following inoculation with diazotrophic bacteria. Plant Soil 284, 23-32. doi: 10.1007/s11104-006-0025-0

Di Salvo, L. P., Cellucci, G. C., Carlino, M. E., and García De Salamone, I. E. (2018). Plant growth-promoting rhizobacteria inoculation and nitrogen fertilization increase maize (Zea mays L.) grain yield and modified rhizosphere microbial communities. Appl. Soil Ecol. 126, 113-120. doi: 10.1016/j.apsoil.2018.02.010

Drogue, B., Doré, H., Borland, S., Wisniewski-Dyé, F., and PrigentCombaret, C. (2012). Which specificity in cooperation between phytostimulating rhizobacteria and plants? Res. Microbiol. 163, 500-510. doi: 10.1016/j.resmic.2012.08.006

Ehteshami, S. M., Aghaalikhani, M., Khavazi, K., and Chaichi, M. R. (2007). Effect of phosphate solubilizing microorganisms on quantitative and qualitative characteristics of maize (Zea mays L.) under water deficit stress. Pak. J. Biol. Sci. 10, 3585-3591. doi: 10.3923/pjbs.2007.3585.3591

Ferreira, C. M. H., Soares, H., and Soares, E. V. (2019). Promising bacterial genera for agricultural practices: an insight on plant growth-promoting properties and microbial safety aspects. Sci Total Environ. 682, 779-799. doi: 10.1016/j.scitotenv.2019.04.225

Gamalero, E., Trotta, A., Massa, N., Copetta, A., Martinotti, M. G., and Berta, G. (2004). Impact of two fluorescent pseudomonads and an arbuscular mycorrhizal fungus on tomato plant growth, root architecture and $\mathrm{P}$ acquisition. Mycorrhiza 14, 185-192. doi: 10.1007/s00572-003-0256-3

García De Salamone, I. E., Di Salvo, L. P., Escobar Ortega, J. S., Boa Sorte, P. M. F., Urquiaga, S., and Teixeira, K. R. S. (2010). Field response of rice paddy crop to Azospirillum inoculation: physiology of rhizosphere bacterial communities and the genetic diversity of endophytic bacteria in different parts of the plants. Plant Soil 336, 351-362. doi: 10.1007/s11104-010-0487-y

Glick, B. R. (2003). Phytoremediation: synergistic use of plants and bacteria to clean up the environment. Biotechnol. Adv. 21, 383-393. doi: 10.1016/S0734-9750(03)00055-7

Good, A. G., and Beatty, P. H. (2011). Fertilizing nature: a tragedy of excess in the commons. PLoS Biol. 9:e1001124. doi: 10.1371/journal.pbio.1001124 
Gulati, A., Vyas, P., Rahi, P., and Kasana, R. C. (2009). Plant growth-promoting and rhizosphere-competent Acinetobacter rhizosphaerae strain BIHB 723 from the cold deserts of the Himalayas. Curr. Microbiol. 58, 371-377. doi: 10.1007/s00284-008-9339-x

Haghanifar, S., Hamidi, A., and Llikaee, M. N. (2018). Effect of treatment by carboxin thiram fungicide and imidacoloroprid pesticide on some indicators of seed germination and vigor of maize (zea mays 1.) single cross hybrid704. Iranian J. Seed Cience Technol. 7, 4-20. doi: 10.22034/ijsst.2018.117054

Hansen, E., and Donohoe, M. (2003). Health issues of migrant and seasonal farmworkers. J. Health Care Poor Underserv. 14, 153-164. doi: 10.1353/hpu.2010.0790

Hassan, W., Bano, R., Bashir, F., and David, J. (2014). Comparative effectiveness of ACC-deaminase and/or nitrogen-fixing rhizobacteria in promotion of maize (Zea mays L.) growth under lead pollution. Environ. Sci. Pollut. Res. Int. 21, 10983-10996. doi: 10.1007/s11356-014-3083-5

Hungria, M., Nogueira, M. A., and Araujo, R. S. (2013). Co-inoculation of soybeans and common beans with rhizobia and azospirilla: strategies to improve sustainability. Biol. Fertil. Soils 49, 791-801. doi: 10.1007/s00374-012-0771-5

Kampers, L. F. C., Volkers, R. J. M., and Martins Dos Santos, V. A. P. (2019). Pseudomonas putida KT2440 is HV1 certified, not GRAS. Microb. Biotechnol. 12, 845-848. doi: 10.1111/1751-7915.13443

Keswani, C., Prakash, O., Bharti, N., Vílchez, J. I., Sansinenea, E., Lally, R. D., et al. (2019). Re-addressing the biosafety issues of plant growth promoting rhizobacteria. Sci. Total Environ. 690, 841-852. doi: 10.1016/j.scitotenv.2019.07.046

Kumar, B., Trivedi, P., and Pandey, A. (2007). Pseudomonas corrugata: a suitable bacterial inoculant for maize grown under rainfed conditions of Himalayan region. Soil Biol. Biochem. 39, 3093-3100. doi: 10.1016/j.soilbio.2007.07.003

Lally, R. D., Galbally, P., Moreira, A. S., Spink, J., Ryan, D., Germaine, K. J., et al. (2017). Application of endophytic Pseudomonas fluorescens and a bacterial consortium to Brassica napus can increase plant height and biomass under greenhouse and field conditions. Front. Plant Sci. 8:2193. doi: 10.3389/fpls.2017.02193

Lavakush, Y. J., Verma, J. P., Jaiswal, D. K., and Kumar, A. (2014). Evaluation of PGPR and different concentration of phosphorus level on plant growth, yield and nutrient content of rice (Oryza sativa). Ecol. Eng. 62, 123-128. doi: 10.1016/j.ecoleng.2013.10.013

Lin, H. R., Shu, H. Y., and Lin, G. H. (2018). Biological roles of indole3-acetic acid in Acinetobacter baumannii. Microbiol. Res. 216, 30-39. doi: 10.1016/j.micres.2018.08.004

Marks, B. B., Megías, M., Nogueira, M. A., and Hungria, M. (2013). Biotechnological potential of rhizobial metabolites to enhance the performance of Bradyrhizobium spp. and Azospirillum brasilense inoculants with soybean and maize. AMB Express 3:21. doi: 10.1186/2191-0855-3-21

Molina-Romero, D., Baez, A., Quintero-Hernandez, V., Castaneda-Lucio, M., Fuentes-Ramirez, L. E., Bustillos-Cristales, M. D. R., et al. (2017). Compatible bacterial mixture, tolerant to desiccation, improves maize plant growth. PLoS ONE 12:e0187913. doi: 10.1371/journal.pone.0187913

Moradtalab, N., Ahmed, A., Geistlinger, J., Walker, F., Höglinger, B., Ludewig, U., et al. (2020). Synergisms of microbial consortia, $\mathrm{N}$ forms, and micronutrients alleviate oxidative damage and stimulate hormonal cold stress adaptations in maize. Front. Plant Sci.11:396. doi: 10.3389/fpls.2020.00396

Morales-García, Y. E., Baez, A., Quintero-Hernández, V., Molina-Romero, D., Rivera-Urbalejo, A. P., Pazos-Rojas, L. A., et al. (2019). "Bacterial mixtures, the future generation of inoculants for sustainable crop production," in Field Crops: Sustainable Management by PGPR, eds D. K. Maheshwari and S. Dheeman (Cham: Springer International Publishing), 11-44.

Morales-García, Y. E., Juárez-Hernández, D., Aragón-Hernández, C., MascaruaEsparza, M. A., Bustillos-Cristales, M. R., Fuentes-Ramírez, L. E., et al. (2011). Growth response of maize plantlets inoculated with Enterobacter spp., as a model for alternative agriculture. Rev. Argentina Microbiol. 43, 287-293. doi: 10.1590/S0325-75412011000400009

Mpanga, I. K., Nkebiwe, P. M., Kuhlmann, M., Cozzolino, V., Piccolo, A., Geistlinger, J., et al. (2019). The form of $\mathrm{N}$ supply determines plant growth promotion by P-solubilizing microorganisms in maize. Microorganisms 7:111. doi: 10.3390/microorganisms7020038

Mrkovački, N., ðalović, I., Jošić, D., Bjelić, D., and Brdar-Jokanović, M. (2016). The effect of PGPR strains on microbial abundance in maize rhizosphere in field conditions. Institut za Ratarstvo i Povrtarstvo Novi Sad 53, 15-19. doi: $10.5937 /$ ratpov53-8224

Muñoz-Rojas, J., and Caballero-Mellado, J. (2003). Population dynamics of Gluconacetobacter diazotrophicus in sugarcane cultivars and its effect on plant growth. Microb. Ecol. 46, 454-464. doi: 10.1007/s00248-003-0110-3

Murashige, T., and Skoog, F. (1962). A revised medium for rapid growth and bio assays with tobacco tissue cultures. Physiol. Plantarum 15, 473-497. doi: 10.1111/j.1399-3054.1962.tb08052.x

Myresiotis, C. K., Vryzas, Z., and Papadopoulou-Mourkidou, E. (2015). Effect of specific plant-growth-promoting rhizobacteria (PGPR) on growth and uptake of neonicotinoid insecticide thiamethoxam in corn (Zea mays L.) seedlings. Pest Manag. Sci. 71, 1258-1266. doi: 10.1002/ps.3919

Naseri, R., and Mirzaei, A. (2010). Response of yield and yield components of safflower (Carthamus tinctorius L.) to seed inoculation with Azotobacter and Azospirillum and different nitrogen levels under dry land conditions. Am. Eur. J. Agric. Environ. Sci. 9, 445-449.

Naveed, M., Khalid, M., Jones, D. L., Ahmad, R., and Zahir, Z. A. (2008). Relative efficacy of Pseudomonas spp., containing ACC-deaminase for improving growth and yield of maize (Zea mays L.) in the presence of organic fertilizer. Pak. J. Bot. 40, 1243-1251.

Nosheen, A., Bano, A., Yasmin, H., Keyani, R., Habib, R., Shah, S. T., et al. (2016). Protein quantity and quality of safflower seed improved by NP fertilizer and rhizobacteria (Azospirillum and Azotobacter spp.). Front. Plant Sci. 7:104. doi: 10.3389/fpls.2016.00104

Okuno, A., Hirano, K., Asano, K., Takase, W., Masuda, R., Morinaka, Y., et al. (2014). New approach to increasing rice lodging resistance and biomass yield through the use of high gibberellin producing varieties. PLOS ONE 9:e86870. doi: 10.1371/journal.pone.0086870

Pazos-Rojas, L. A., Muñoz-Arenas, L. C., Rodríguez-Andrade, O., López-Cruz, L. E., López-Ortega, O., Lopes-Olivares, F., et al. (2019). Desiccation-induced viable but nonculturable state in Pseudomonas putida KT2440, a survival strategy. PLoS ONE 14:e0219554. doi: 10.1371/journal.pone.0219554

Pereira, N. C. M., Galindo, F. S., Gazola, R. P. D., Dupas, E., Rosa, P. A. L., Mortinho, E. S., et al. (2020). Corn yield and phosphorus use efficiency response to phosphorus rates associated with plant growth promoting bacteria. Front. Environ. Sci. 8:40. doi: 10.3389/fenvs.2020.00040

Pii, Y., Aldrighetti, A., Valentinuzzi, F., Mimmo, T., and Cesco, S. (2019). Azospirillum brasilense inoculation counteracts the induction of nitrate uptake in maize plants. J. Exp. Bot. 70, 1313-1324. doi: 10.1093/jxb/ery433

Piromyou, P., Buranabanyat, B., Tantasawat, P., Tittabutr, P., Boonkerd, N., and Teaumroong, N. (2011). Effect of plant growth promoting rhizobacteria (PGPR) inoculation on microbial community structure in rhizosphere of forage corn cultivated in Thailand. Eur. J. Soil Biol. 47, 44-54. doi: 10.1016/j.ejsobi.2010.11.004

Planchamp, C., Glauser, G., and Mauch-Mani, B. (2014). Root inoculation with Pseudomonas putida KT2440 induces transcriptional and metabolic changes and systemic resistance in maize plants. Front. Plant Sci. 5:719. doi: 10.3389/fpls.2014.00719

Ramírez, V., Baez, A., López, P., Bustillos, R., Villalobos, M. Á., Carreño, R., et al. (2019). Chromium hyper-tolerant Bacillus sp. MH778713 assists phytoremediation of heavy metals by mesquite trees (Prosopis laevigata). Front. Microbiol. 10:1833. doi: 10.3389/fmicb.2019.01833

Ramírez, V., Munive, J.-A., Cortes, L., Muñoz-Rojas, J., Portillo, R., and Baez, A. (2020). Long-chain hydrocarbons (C21, C24, and C31) released by Bacillus sp. MH778713 break dormancy of mesquite seeds subjected to chromium stress. Front. Microbiol. 11:741. doi: 10.3389/fmicb.2020.00741

Rodríguez-Andrade, O., Fuentes-Ramírez, L. E., Morales-García, Y. E., Molina-Romero, D., Bustillos-Cristales, M. R., Martínez-Contreras, R. D., et al. (2015). The decrease in the population of Gluconacetobacter diazotrophicus in sugarcane after nitrogen fertilization is related to plant physiology in split root experiments. Rev. Argentina Microbiol. 47, 335-343. doi: 10.1016/j.ram.2015.09.004

Rojas-Tapias, D. F., Bonilla, R., and Dussán, J. (2014). Effect of inoculation and co-inoculation of Acinetobacter sp. RG30 and Pseudomonas putida GN04 on growth, fitness, and copper accumulation of maize (Zea mays). Water Air Soil Pollut. 225:2232. doi: 10.1007/s11270-014-2232-2

Rosa, P. A. L., Mortinho, E. S., Jalal, A., Galindo, F. S., Buzetti, S., Fernandes, G. C., et al. (2020). Inoculation with growth-promoting bacteria associated with 
the reduction of phosphate fertilization in sugarcane. Front. Environ. Sci. 8:32. doi: $10.3389 /$ fenvs.2020.00032

Rozier, C., Hamzaoui, J., Lemoine, D., Czarnes, S., and Legendre, L. (2017). Field-based assessment of the mechanism of maize yield enhancement by Azospirillum lipoferum CRT1. Sci. Rep. 7:7416. doi: 10.1038/s41598-017-07929-8

Sánchez, A. C., Gutiérrez, R. T., Santana, R. C., Urrutia, A. R., Fauvart, M., Michiels, J., et al. (2014). Effects of co-inoculation of native Rhizobium and Pseudomonas strains on growth parameters and yield of two contrasting Phaseolus vulgaris L. genotypes under Cuban soil conditions. Eur. J. Soil Biol. 62, 105-112. doi: 10.1016/j.ejsobi.2014.03.004

Schröder, P., Beckers, B., Daniels, S., Gnädinger, F., Maestri, E., Marmiroli, N., et al. (2018). Intensify production, transform biomass to energy and novel goods and protect soils in Europe-a vision how to mobilize marginal lands. Sci. Total Environ. 616-617, 1101-1123. doi: 10.1016/j.scitotenv.2017.10.209

Shahzad, S. M., Arif, M. S., Riaz, M., Iqbal, Z., and Ashraf, M. (2013). PGPR with varied ACC-deaminase activity induced different growth and yield response in maize (Zea mays L.) under fertilized conditions. Eur. J. Soil Biol. 57, 27-34. doi: 10.1016/j.ejsobi.2013.04.002

Shahzad, S. M., Khalid, A., Arif, M. S., Riaz, M., Ashraf, M., Iqbal, Z., et al. (2014). Co-inoculation integrated with P-enriched compost improved nodulation and growth of Chickpea (Cicer arietinum L.) under irrigated and rainfed farming systems. Biol. Fertil. Soils 50, 1-12. doi: 10.1007/s00374-013-0826-2

Sheng, X., Sun, L., Huang, Z., He, L., Zhang, W., and Chen, Z. (2012). Promotion of growth and $\mathrm{Cu}$ accumulation of bio-energy crop (Zea mays) by bacteria: implications for energy plant biomass production and phytoremediation. $J$. Environ. Manage 103, 58-64. doi: 10.1016/j.jenvman.2012.02.030

Singh, A., Jain, A., Sarma, B. K., Upadhyay, R. S., and Singh, H. B. (2014). Rhizosphere competent microbial consortium mediates rapid changes in phenolic profiles in chickpea during Sclerotium rolfsii infection. Microbiol. Res. 169, 353-360. doi: 10.1016/j.micres.2013.09.014

Singh, G., Singh, N., and Marwaha, T. S. (2009). Crop genotype and a novel symbiotic fungus influences the root endophytic colonization potential of plant growth promoting rhizobacteria. Physiol. Mol. Biol. Plants 15, 87-92. doi: 10.1007/s12298-009-0009-7

Sundaramoorthy, S., Raguchander, T., Ragupathi, N., and Samiyappan, R. (2012). Combinatorial effect of endophytic and plant growth promoting rhizobacteria against wilt disease of Capsicum annum L. caused by Fusarium solani. Biol. Control 60, 59-67. doi: 10.1016/j.biocontrol.2011.10.002
Tilman, D., Cassman, K. G., Matson, P. A., Naylor, R., and Polasky, S. (2002). Agricultural sustainability and intensive production practices. Nature 418, 671-677. doi: 10.1038/nature01014

Vacheron, J., Desbrosses, G., Bouffaud, M. L., Touraine, B., Moenne-Loccoz, Y., Muller, D., et al. (2013). Plant growth-promoting rhizobacteria and root system functioning. Front. Plant Sci. 4:19. doi: 10.3389/fpls.20 13.00356

Vaikuntapu, P. R., Dutta, S., Samudrala, R. B., Rao, V. R., Kalam, S., and Podile, A. R. (2014). Preferential promotion of Lycopersicon esculentum (Tomato) growth by plant growth promoting bacteria associated with tomato. Indian J. Microbiol. 54, 403-412. doi: 10.1007/s12088-014-0470-z

Vílchez, J. I., Navas, A., González-López, J., Arcos, S. C., and Manzanera, M. (2015). Biosafety test for plant growth-promoting bacteria: proposed Environmental and Human Safety Index (EHSI) protocol. Front. Microbiol. 6:1514. doi: 10.3389/fmicb.2015.01514

Visnovsky, S. B., Panda, P., Everett, K. R., Lu, A., Butler, R. C., Taylor, R. K., et al. (2020). A PCR diagnostic assay for rapid detection of plant pathogenic pseudomonads. Plant Pathol. 69, 1311-1330. doi: 10.1111/ppa.13204

Wang, C. J., Yang, W., Wang, C., Gu, C., Niu, D. D., Liu, H. X., et al. (2012). Induction of drought tolerance in cucumber plants by a consortium of three plant growth-promoting rhizobacterium strains. PLOS ONE 7:e52565. doi: 10.1371 /journal.pone.0052565

Zahid, M., Abbasi, M. K., Hameed, S., and Rahim, N. (2015). Isolation and identification of indigenous plant growth promoting rhizobacteria from Himalayan region of Kashmir and their effect on improving growth and nutrient contents of maize (Zea mays L.). Front. Microbiol. 6:207. doi: $10.3389 /$ fmicb.2015.00207

Conflict of Interest: The authors declare that the research was conducted in the absence of any commercial or financial relationships that could be construed as a potential conflict of interest.

Copyright $\odot 2021$ Molina-Romero, Juárez-Sánchez, Venegas, Ortíz-González, Baez, Morales-García and Muñoz-Rojas. This is an open-access article distributed under the terms of the Creative Commons Attribution License (CC BY). The use, distribution or reproduction in other forums is permitted, provided the original author(s) and the copyright owner(s) are credited and that the original publication in this journal is cited, in accordance with accepted academic practice. No use, distribution or reproduction is permitted which does not comply with these terms. 